\title{
PENGARUH PERSEPSI PENGETAHUAN, INFORMASI, DAN RELIGIUSITAS TERHADAP MINAT BERWAKAF UANG
}

\author{
Rizkie Anugerah Pramudia ${ }^{\mathrm{a}}$ \\ Mochamad Edman Syarief ${ }^{b}$ \\ a,bPoliteknik Negeri Bandung

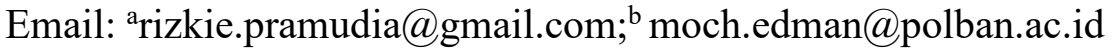

\begin{abstract}
This study aims to determine the perception of the Muslim community in West Java on cash waqf. The variables used in this study were knowledge, information and religiosity variables. This research is a quantitative study using Structural Equation Model-Partial Least Square (SEM-PLS) with the WarpPLS tool. The results showed that the variables of knowledge, information and religiosity had a positive effect on the interest to donating cash waqf. Positive public perceptions of cash waqf need to be supported by more massive socialization and education. Obviously, proper regulations also need to be prepared so that the purpose of cash waqf is achieved.
\end{abstract}

Keywords : Cash Waqf, Perception, Knowledge, Information, Religiosity

\section{PENDAHULUAN}

Sebagai negara dengan populasi muslim terbesar di dunia, umat Islam dapat memberikan peran terbaiknya melalui berbagai bentuk atau model filantropi dalam ekonomi dan keuangan syariah. Peran ini diharapkan dapat mengatasi guncangan ekonomi yang terjadi dan seluruh masyarakat, khususnya umat muslim, dapat ikut serta berkontribusi dalam memulihkan guncangan tersebut (Azwar, 2020). Salah satu solusi yang ditawarkan sektor keuangan sosial Islam menghadapi krisis adalah melalui Zakat, Infak, Sedekah dan Wakaf (Ziswaf). Sayangnya saat ini peran wakaf masih belum optimal untuk menangani pandemi Covid-19 (virus corona). Menurut Badan Wakaf Indonesia, dana yang disampaikan kepada mereka yang terkena dampak lebih banyak bersumber dari Zakat, Infak dan Sedekah (ZIS) karena pada umumnya umat Islam lebih terfokus pada wakaf yang bersifat benda yang memiliki nilai tinggi, seperti tanah, bangunan, sumur untuk diambil airnya, ataupun pohon yang dapat diambil buahnya sedangkan pengelolaan wakaf tunai masih tergolong baru berkembang beberapa tahun terakhir (Putra, 2020).

Menurut (Nasution, 2005), potensi wakaf di Indonesia dengan jumlah umat Muslim yang dermawan diperkirakan sebesar 10 juta jiwa dengan rata-rata penghasilan $\mathrm{Rp} 500.000$ hingga $\mathrm{Rp}$ 10.000.000, maka paling tidak akan terkumpul dana sekitar 3 triliun per tahun dari dana wakaf seperti perhitungan tabel berikut: 


\begin{tabular}{|c|c|c|c|c|}
\hline $\begin{array}{c}\text { Tingkat } \\
\text { penghasilan/bulan }\end{array}$ & $\begin{array}{l}\text { Jumlah } \\
\text { muslim }\end{array}$ & $\begin{array}{c}\text { Besaran } \\
\text { wakaf/bulan }\end{array}$ & $\begin{array}{c}\text { Potensi wakaf } \\
\text { uang/bulan }\end{array}$ & $\begin{array}{l}\text { Potensi wakaf } \\
\text { uang/tahun }\end{array}$ \\
\hline Rp 500.000 & 4 Juta & Rp 5.000 & Rp 20 Milyar & Rp 240 Milyar \\
\hline Rp $1-2$ Juta & 3 juta & Rp 10.000 & Rp 30 Milyar & Rp 360 Milyar \\
\hline Rp 2-5 Juta & 2 Juta & Rp 50.000 & Rp 100 Milyar & Rp 1.2 Trilyun \\
\hline$\geq$ Rp 5 Juta & 1 Juta & Rp 100.000 & Rp 100 Milyar & Rp 1.2 Trilyun \\
\hline \multicolumn{4}{|c|}{ Total } & Rp 3 Trilyun \\
\hline
\end{tabular}

Sumber : Nasution (2005)

Terkait dengan populasi muslim yang besar, Provinsi Jawa Barat merupakan provinsi yang masyarakat pemeluk islamnya terbanyak di Indonesia yaitu sebesar 41.314.121 jiwa (Badan Pusat Statistik, 2019). Potensi ekonomi syariah di Jawa Barat menurut Wakil Gubernur Jawa Barat, Uu Ruzhanul Ulum, sangat besar jika dilihat dari jumlah penduduk yang muslim dan jumlah pesantren. Beliau menambahkan ada keterangan dalam Islam bahwa masuklah ke dalam Islam secara kaffah, jadi menurutnya melaksanakan ekonomi atau muamalah syariah adalah sebuah keharusan (Pemerintah Provinsi Jawa Barat, 2020).

Penelitian yang dilakukan kepada jama'ah masjid Daarut Tauhid Kota Bandung pada tahun 2017, menghasilkan fakta bahwa persepsi masyarakat terhadap wakaf uang tidak cukup baik, padahal tingkat religiusitas dan tingkat pendidikan jama'ah atau pun masyarakat sekitar terkategori cukup tinggi karena berdekatan dengan pusat pendidikan dan dalam lingkungan pesantren. Tingkat religiusitas secara positif signifikan berpengaruh terhadap persepsi jama'ah masjid Daarut Tauhid mengenai wakaf uang (Dewi, 2017). Penelitian lain yang dilakukan di kota Bogor pada tahun 2015 mengenai persepsi masyarakat kota Bogor terhadap wakaf uang yang diklasifikasikan berdasarkan pendidikan dan pekerjaan. Variabel yang digunakan dalam penelitian ini adalah variabel pengetahuan, minat, dan media informasi. Hasilnya, variabel pengetahuan memiliki perngaruh sangat besar terhadap minat masyarakat dalam berwakaf tunai. Variabel media informasi juga berpengaruh terhadap minat masyarakat dalam berwakaf tunai, sehingga diperlukan sosialisasi di berbagai media informasi agar minat berwakaf tunai terus meningkat (Handayani \& Kurnia, 2015).

Berdasarkan hal tersebut, maka penulis bermaksud melakukan penelitian dalam ruang lingkup yang lebih luas untuk mengetahui persepsi masyarakat muslim Jawa Barat terhadap wakaf uang baik dalam variabel pengetahuan, informasi dan religiusitas. Penulis menduga berdasarkan beberapa penelitian terdahulu, kurangnya pengetahuan dan informasi terkait wakaf uang membuat potensi wakaf uang menjadi sulit dioptimalkan. Tujuan dari penelitian ini adalah untuk mengetahui persepsi masyarakat muslim di Jawa Barat pengetahuan, informasi dan religiusitas terhadap minat berwakaf uang.

\section{WAKAF UANG}

Wakaf uang didefinisikan sebagai dana atau uang yang dihimpun oleh lembaga pengelola wakaf (nadzhir) melalui penerbitan sertifikat yang dibeli oleh masyarakat. Dalam istilah lain wakaf uang juga dapat diartikan sebagai 
sumbangan harta dalam bentuk uang atau surat berharga yang dikelola oleh lembaga perbankan atau lembaga keuangan syariah yang keuntungannya akan dibagikan namun modalnya tidak dapat dikurangi meskipun untuk sedekah. Sementara dana wakaf yang terkumpul kemudian bisa disalurkan dan diinvestasikan oleh nadzhir ke berbagai bisnis sektor-sektor yang halal dan produktif, sehingga keuntungannya dapat dimanfaatkan untuk kesejahteraan masyarakat secara keseluruhan (Gustani \& Ernawan, 2016).

$\begin{array}{llr}\text { Wahbah Zuhaili menjelaskan } \\ \text { bahwa ulama } \\ \text { memperbolehkan } & \text { wakhab Maliki }\end{array}$
mengingat manfaat uang masih dalam cakupan hadits Nabi Muhammad Shallallaahu'alaihi Wassallam dan benda sejenis yang diwakafkan oleh para sahabat, seperti baju perang, binatang, dan harta lainnya serta hal tersebut mendapat pengakuan dari Rasulullah Shallallaahu'alaihi Wassallam. Secara Qiyas, wakaf uang dianalogikan dengan baju perang dan binatang. Qiyas ini telah memenuhi syari'at 'illah (sebab persamaan) dalam qiyas dan yang diqiyaskan (maqis dan maqis 'alaih). Sama-sama benda bergerak dan tidak kekal, yang mungkin rusak dalam waktu tertentu, bahkan wakaf uang jika dikelola secara professional memungkinkan uang yang diwakafkan kekal selamanya (Hidayatullah, 2016).

\section{MINAT DAN PERSEPSI}

Minat diartikan kesediaan jiwa yang sifatnya aktif untuk menerima sesuatu dari luar (Poerbakawatja \& Harahap, 2012). Pengertian yang paling mendasar tentang minat dikemukakan oleh (The Liang Gie, 2014), minat artinya sibuk, tertarik, atau terlibat dengan sesuatu kegiatan karena menyadari pentingnya suatu kegiatan.
Berdasarkan beberapa pengertian minat yang dikemukakan oleh para ahli, maka dapat diasumsikan bahwa minat adalah suatu pemusatan perhatian yang mengandung unsur-unsur perasaan, kesenangan, kecenderungan hati, keinginan yang tidak disengaja yang sifatnya aktif untuk menerima sesuatu dari luar. Minat adalah sesuatu yang sangat penting bagi seseorang untuk melakukan suatu aktivitas. Dengan minat orang akan berusaha mencapai tujuannya. Oleh karena itu minat dikatakan sebagai salah satu aspek psikis manusia yang dapat mendorong untuk mencapai tujuan (P., 2019).

Persepsi adalah proses dimana organisme menafsirkan dan mengatur sensasi untuk menghasilkan pengalaman dunia yang bermakna (Lindsay \& Norman, 1977). Dengan kata lain, seseorang dihadapkan pada situasi atau rangsangan. Orang tersebut menafsirkan rangsangan menjadi sesuatu yang berarti baginya berdasarkan pengalaman sebelumnya. Namun, apa yang ditafsirkan atau dirasakan oleh seseorang mungkin sangat berbeda dari kenyataan (Dobson, 2005).

\section{HUBUNGAN PENGETAHUAN DAN MINAT BERWAKAF UANG}

Ada tiga macam pengetahuan yang dijelaskan (Dombrowski et al., 2013), diantaranya; a) Experiential knowledge, b) Skills, dan c) Knowledge claims. Semuanya saling berkaitan, namun memiliki ciri khasnya masingmasing. Experiential knowledge adalah apa didapatkan dari hubungan langsung dengan lingkungan, melalui sistem sensorik dan kemudian diproses oleh otak. Skills berarti pengetahuan tentang bagaimana melakukan sesuatu (knowhow). Pengetahuan ini adalah pengetahuan yang terstruktur dengan baik dan berorientasi pada tindakan 
yang didapatkan dengan melakukan kegiatan tertentu dan mempelajarinya berulang kali. Knowledge claims adalah pengetahuan yang diketahui atau dirasa diketahui secara eksplisit atau jelas dan juga pengetahuan yang dipahami tanpa perlu diucapkan secara gamblang (Bolisani \& Bratianu, 2018).

Falahuddin (2019) berpendapat bahwa salah satu faktor yang mempengaruhi minat melakukan wakaf adalah pengetahuan, walaupun ridak signifikan secara statistik. Hal yang berbeda dijelaskan oleh Rawanti dan Murtani (2019), bahwa pengetahuan berpengaruh positif dan signifikan terhadap minat masyarakat untuk melakukan wakaf. Selain itu, pengetahuan juga berpengaruh terhadap minat membayar zakat (Nugroho et al., 2019; Sahal et al., 2020). Dengan demikian maka hipotesis yang diajukan adalah $\mathrm{H}_{1}$ : pengetahuan berpengaruh positif terhadap minat berwakaf uang.

\section{HUBUNGAN INFORMASI DAN MINAT BERWAKAF UANG}

Beberapa teori mengenai definisi informasi diulas oleh McCreadie \& Rice (1999). Informasi sebagai representasi dari pengetahuan yang disimpan. Secara tradisional media penyimpanan informasi adalah buku, tetapi saat ini media elektronik semakin penting sebagai media informasi. lnformasi juga dianggap sebagai data lingkungan karena diperoleh dari berbagai rangsangan dan fenomena lingkungan, secara keseluruhan tidak dimaksudkan untuk pengantar pesan, tetapi dapat menjadi informatif bila diinterpretasikan secara tepat. Informasi juga sebagai bagian dari proses komunikasi, maknanya lebih dari sekedar kata-kata atau data. Waktu dan faktor interaksi sosial memainkan peran penting dalam proses dan interpretasi informasi. Informasi dapat dikatakan sebagai sumber daya atau komoditas karena informasi ditransmisikan dalam sebuah pesan dari pengirim pesan ke penerima pesan sehingga penerima pesan dapat menafsirkan pesan sebagaimana dimaksud oleh pengirim pesan (Madden, 2000).

Penelitian Ash-Shidiqqy (2019) menyatakan bahwa informasi tidak berpengaruh terhadap minat masyarakat untuk membayar wakaf. Hal ini bisa jadi terjadi karena kurangnya sosialisasi kepada masyarakat (Rusydiana dan Rahayu, 2019). Dilain pihak, Handayani dan Kurnia (2015) menyatakan bahwa salah satu faktor yang membedakan minat masyarakat untuk melakukan wakaf adalah media informasi. Dengan demikian, apabila sosialisasi wakaf kepada masyarakat dilakukan dengan gencar, maka kemungkinan besar minat masyarakat dalam berwakaf uang juga akan meningkat. Berdasarkan hal tersebut, maka hipotesis yang diajukan adalah $\mathrm{H}_{2}$ : Informasi berpengrauh positif terhadap minat berwakaf uang.

\section{HUBUNGAN RELIGIUSITAS DAN MINAT BERWAKAF UANG}

Menurut (Adeyemo \& Adeleye, 2008) religiusitas termasuk meyakini, menghormati Tuhan, serta partisipasi dalam kegiatan dalam balutan keimanan, seperti menghadiri ibadah secara teratur dan berpartisipasi dalam kegiatan sosial. Definisi religiusitas yang sangat populer menyatakan bahwa religiusitas berarti kepercayaan kepada Tuhan yang sejalan dengan komitmen untuk mengikuti prinsip-prinsip yang ditetapkan oleh Tuhan. Terpstra dan David (1991) mendefinisikan religiusitas sebagai seperangkat keyakinan, ide, dan tindakan yang dibagikan secara sosial yang berhubungan dengan realitas yang tidak dapat diverifikasi (Mathur et al., 2015). 
Benerapa penelitian menyatakan bahwa religiusitas berpengaruh terhadap minat seseorang untuk melaksanakan kewajiban sosial, seperti zakat. Satrio (2016) menyatakan bahwa religiusitas berpengaruh terhadap minat membayar zakat melalui Lembaga Amil Zakat. Hal yang sama juga dikemukakan oleh AshShiddiqy (2019) yang berpendapat bahwa religiusitas berpengaruh positif terhadap minat masyarakat untuk membayar wakaf. Nugroho (2019) berpendapat bahwa religiusitas tidak berpengaruh secara langsung terhadap minat muzakki dalam membayar zakat profesi. Berdasarkan hal tersebut, maka hipotesis yang diajukan adalah $\mathrm{H}_{3}$ : religiusitas berpengaruh positif terhadap minat wakaf uang

\section{METODE PENELITIAN}

Penelitian ini merupakan penelitian kuantitatif dengan pengumpulan data yang dipilih adalah pengumpulan data primer, dengan cara menyebarkan kuesioner ke responden. Kuesioner yang disebarkan kepada responden dilakukan melalui media sosial yang terintegrasi dengan google form, sedangkan teknik analisis data menggunakan analisis model Partial Least Square (PLS). Populasi yang ditentukan adalah masyarakat muslim di daerah Bandung dan sekitarnya, dengan jumlah sampel sebesar 181 responden. Jumlah ini sudah melebihi jumlah sampel minimal yang diperlukan untuk melakukan analisis data dengan menggunakan Warp-Pls yaitu sebanyak 148 sampel (Kock \& Hadaya, 2018b).

\section{HASIL DAN PEMBAHASAN} 1. Gambaran Umum Responden

Gambaran umum responden yang disurvei untuk mengetahui persepsi masyarakat muslim di Jawa Barat antara lain berdasarkan jenis kelamin, usia, pendidikan terakhir, pekerjaan, penghasilan per bulan dan domisili.

\section{a. Jenis Kelamin}

Responden pada penelitian ini didominasi oleh responden berjenis kelamin wanita. Meskipun didominasi responden wanita, namun jumlahnya tidak begitu jauh dengan jumlah responden pria sebanyak 85 responden, terlihat pada tabel 2 :

Tabel 2. Jenis Kelamin Responden

\begin{tabular}{|c|c|c|}
\hline Jenis Kelamin & Jumlah & Persentase \\
\hline Pria & 85 & $47 \%$ \\
\hline Wanita & 96 & $53 \%$ \\
\hline Total & 181 & $100 \%$ \\
\hline
\end{tabular}

Sumber: Data diolah (2020)

\section{b. Usia}

Responden pada penelitian ini terbatas pada usia dewasa, yaitu diatas 18 tahun. Usia dewasa dipilih karena usia dewasa adalah usia pada saat seorang individu peran dan tanggung jawabnya semakin bertambah besar. Dimana sudah mulai melepaskan diri dari ketergantungan terhadap orang lain terutama dari orang tua, baik secara ekonomis, sosiologis ataupun psikologis. Seseorang yang telah dewasa akan lebih mengupayakan untuk menjadi orang yang lebih mandiri lagi, segala upaya akan dilakuan agar tidak bergantung lagi kepada orang lain (Putri, 2018). Harapan penulis dengan pembatasan usia ini agar responden dapat menjawab kuesioner dengan penuh tanggungjawab sehingga data yang didapat saat penelitian lebih dapat dipertanggungjawabkan hasilnya.

Mayoritas usia responden pada penelitian ini berusia dalam rentang 18 sampai dengan 40 tahun. Responden berusia dalam rentang 41-60 tahun tercatat sebesar 17,7 persen dari total keseluruhan responden. Namun, terjadi ketimpangan pada golongan responden berusia diatas 60 tahun, total responden 
yang tercatat hanya 1 orang responden yang berpartisipasi.

Hasil survei Kementerian Komunikasi dan Informatika Indonesia pada tahun 2017 menunjukkan bahwa lebih dari setengah masyarakat Indonesia sudah memiliki telepon pintar atau smartphone (Kominfo, 2017). Pada tahun 2016 jumlah pengguna internet di Indonesia meningkat menjadi 132,7 juta pengguna. Penetrasi penggunaan media ini tidak merata di berbagai usia. Penetrasi terbesar pengguna internet didominasi oleh masyarakat berumur 25-34 tahun sebesar 78 persen. Sementara itu, penetrasi pengguna internet di kalangan lanjut usia atau lansia (di atas 55 tahun) hanya berjumlah 2 persen. Salah satu penyebabnya adalah ketimpangan antargenerasi yang timbul karena kurangnya keahlian untuk mengakses berbagai macam informasi melalui teknologi digital. Oleh karena itu, kalangan lansia cenderung mengalami gagap teknologi yang lebih besar dibandingkan dengan generasi remaja ketika berhadapan dengan derasnya arus perkembangan teknologi komunikasi (Ashari, 2014). Berdasarkan hal tersebut, maka bisa dipahami bahwa responden pada penelitian ini lebih didominasi oleh responden yang berusia dibawah 60 tahun jika dilihat dalam Tabel 3.

Tabel 3. Usia Responden

\begin{tabular}{|c|c|c|}
\hline Usia & Jumlah & Persentase \\
\hline $18-30$ tahun & 92 & $50,8 \%$ \\
\hline $31-40$ tahun & 56 & $30,9 \%$ \\
\hline $41-60$ tahun & 32 & $17,7 \%$ \\
\hline$>60$ tahun & 1 & $0,6 \%$ \\
\hline Total & 181 & $100 \%$ \\
\hline
\end{tabular}

Sumber: Data diolah (2020)

\section{c. Pendidikan Terakhir}

Pendidikan terakhir responden pada penelitian ini didominasi responden dengan tingkat pendidikan perguruan tinggi, yaitu sebesar 68 persen atau 123 responden disusul responden dengan tingkat pendidikan terakhir SMA dengan 53 responden atau persentase sebesar 29,3 persen. Hal ini sesuai dengan hasil survei Kementerian Komunikasi dan Informatika (Kemenkominfo) Indonesia pada tahun 2017, pengguna smartphone didominasi oleh pelajar atau mahasiswa dari tingkat SMA sampai tingkat magister perguruan tinggi (Kominfo, 2017). Secara rinci persentase jumlah responden berdasarkan pendidikan terakhir dapat dilihat dalam Tabel 4.

Tabel 4. Pendidikan Terakhir

Responden

\begin{tabular}{|c|c|c|}
\hline $\begin{array}{c}\text { Pendidikan } \\
\text { Terakhir }\end{array}$ & Jumlah & Persentase \\
\hline $\begin{array}{c}\text { Tidak mengenyam } \\
\text { pendidikan formal }\end{array}$ & 0 & $0 \%$ \\
\hline SD / Sederajat & 1 & $0,6 \%$ \\
\hline SMP / Sederajat & 4 & $2,2 \%$ \\
\hline SMA / Sederajat & 53 & $29,3 \%$ \\
\hline Perguruan Tinggi & 123 & $68 \%$ \\
\hline Total & 181 & $100 \%$ \\
\hline
\end{tabular}

Sumber: Data diolah (2020)

\section{d. Penghasilan Per Bulan}

Penghasilan per bulan responden penelitian ini didominasi oleh responden berpenghasilan 2,6 juta sampai 5 juta rupiah yang berarti jika dihitung sesuai Upah Minimum Kota/Kabupaten di Jawa Barat Tahun 2020 (Pikiran Rakyat, 2019). Berikut ini data penghasilan responden per bulan yang tersaji pada Tabel 6 :

Tabel 6. Penghasilan Per Bulan

\begin{tabular}{|l|c|c|}
\hline \multicolumn{1}{|c|}{ Penghasilan } & Jumlah & Persentase \\
\hline $\begin{array}{l}\text { Kurang dari } 1 \\
\text { juta rupiah }\end{array}$ & 22 & $12,2 \%$ \\
\hline $\begin{array}{l}1-2,5 \text { juta } \\
\text { rupiah }\end{array}$ & 42 & $23,3 \%$ \\
\hline $\begin{array}{l}2,6-5 \text { juta } \\
\text { rupiah }\end{array}$ & 56 & $31,1 \%$ \\
\hline$>5$ juta rupiah & 33 & $18,3 \%$ \\
\hline Tidak tentu & 27 & $15 \%$ \\
\hline
\end{tabular}




\begin{tabular}{|c|c|c|}
\hline Penghasilan & Jumlah & Persentase \\
\hline Tidak menjawab & 1 & $0,1 \%$ \\
\hline Total & 181 & $100 \%$ \\
\hline
\end{tabular}

Sumber: Data diolah (2020)

\section{Uji Validitas dan Reliabilitas}

\section{Analisis Variabel}

Bagian ini memuat penjelasan hasil uji validitas dan uji reabilitas variable yang digunakan dalam penelitian. Semua indikator pada variabel pengetahuan, informasi dan religiusitas menggunakan skala Likert dengan skoring 1 sampai dengan 5, dengan rincian skor 1 adalah nilai sangat tidak setuju hingga skor 5 menyatakan sangat setuju terhadap pernyataan-pernyataan yang diajukan dalam kuesioner. Kuesioner ini disebarkan melalui google form mulai dari Oktober 2020 sampai dengan November 2020. Sebanyak 185 jawaban kuesioner terkumpul melalui google form dan dari jawaban ini kemudian dipilih 181 jawaban responden karena ada beberapa jawaban responden yang tidak bisa diproses untuk kemudian dianalisis. Ukuran sampel pada penelitian ini telah memenuhi syarat ukuran minimum sampel yang dibutuhkan untuk melakukan analisis dengan pendekatan PLS-SEM pada alat bantu WarpPLS pada tingkat signifikansi 0,05 yaitu sebanyak 146 buah (Kock \& Hadaya, 2018a).

\section{Evaluasi Outer Model}

Dalam mengukur hubungan antara variabel laten dengan indikator yang terbentuk digunakan kriteria p-value lebih kecil atau sama dengan 0,05 dan nilai loading yang muncul lebih besar dari 0.5 (Kock, 2020). Secara keseluruhan, konstruk variabel independen dan variabel dependen memiliki nilai loading diatas 0,5 dan $\mathrm{p}$ value kurang dari 0,001 sama halnya untuk nilai Composite Reliability (CR) dan Cronbach Alpha (CA) semua nilainya diatas nilai batas 0,7 . Apabila salah satu dari nilai CR dan CA berada diatas nilai batas, maka sudah memenuhi reliabilitas data (Kock \& Lynn, 2012). Nilai

Tabel 7. Combine Loading and P-value

\begin{tabular}{|c|c|c|c|c|c|}
\hline \multicolumn{2}{|c|}{ Indikator } & $\begin{array}{l}\text { Loading } \\
\text { value }\end{array}$ & p-value & $\mathbf{C R}$ & $\mathbf{C A}$ \\
\hline \multicolumn{2}{|c|}{ 1, Pengetahuan } & & & 0,892 & 0,860 \\
\hline X1a & Pengetahuan terhadap wakaf uang & 0,766 & $<0,001$ & & \\
\hline $\mathrm{X} 1 \mathrm{~b}$ & Pemahaman tentang hukum wakaf uang & 0,808 & $<0,001$ & & \\
\hline $\mathrm{X} 1 \mathrm{c}$ & Berwakaf uang karena pengaruh orang lain & 0,546 & $<0,001$ & & \\
\hline X1d & Berwakaf berdasarkan pengetahuan dan pendidikan & 0,813 & $<0,001$ & & \\
\hline $\mathrm{X} 1 \mathrm{e}$ & Berwakaf karena pengalaman pribadi & 0,663 & $<0,001$ & & \\
\hline X1f & Mengetahui tempat menunaikan wakaf uang & 0,769 & $<0,001$ & & \\
\hline $\mathrm{X} 1 \mathrm{~g}$ & Keyakinan akan potensi wakaf uang & 0,698 & $<0,001$ & & \\
\hline $\mathrm{X} 1 \mathrm{~h}$ & Mengetahui regulator wakaf di Indonesia & 0,619 & $<0,001$ & & \\
\hline \multicolumn{2}{|c|}{2, Informasi } & & & 0,849 & 0,776 \\
\hline $\mathrm{X} 2 \mathrm{a}$ & Mendapat informasi tentang wakaf uang & 0,821 & $<0,001$ & & \\
\hline $\mathrm{X} 2 \mathrm{~b}$ & Mencari informasi tentang wakaf uang & 0,771 & $<0,001$ & & \\
\hline $\mathrm{X} 2 \mathrm{c}$ & Kontribusi media terhadap sosialisasi wakaf uang & 0,751 & $<0,001$ & & \\
\hline $\mathrm{X} 2 \mathrm{~d}$ & Perlu sosialisasi wakaf uang & 0,591 & $<0,001$ & & \\
\hline $\mathrm{X} 2 \mathrm{e}$ & Informasi fatwa wakaf uang MUI & 0,691 & $<0,001$ & & \\
\hline \multicolumn{2}{|c|}{ 3, Religiusitas } & & & 0,938 & 0,921 \\
\hline
\end{tabular}




\begin{tabular}{|c|l|c|l|l|l|}
\hline \multicolumn{2}{|c|}{ Indikator } & $\begin{array}{c}\text { Loading } \\
\text { value }\end{array}$ & p-value & CR & CA \\
\hline X3a & Ketaatan dalam beribadah & 0,825 & $<0,001$ & & \\
\hline X3b & Sikap selalu ingin berbagi (filantropi) & 0,812 & $<0,001$ & & \\
\hline X3c & Kepatuhan menjalani perintah agama & 0,883 & $<0,001$ & & \\
\hline X3d & Agama sebagai proritas dalam segala hal & 0,871 & $<0,001$ & & \\
\hline X3e & Selalu mempelajari agama secara mendalam & 0,830 & $<0,001$ & & \\
\hline X3f & Selalu meluangkan waktu untuk beribadah & 0,857 & $<0,001$ & & \\
\hline 4, Minat Berwakaf Uang & & & 0,918 & 0,888 \\
\hline Ya & Minat berwakaf uang di lingkungan sendiri & 0,807 & $<0,001$ & & \\
\hline Yb & Minat berwakaf uang di masjid lingkungan sendiri & 0,845 & $<0,001$ & & \\
\hline Yc & Minat berwakaf uang secara rutin & 0,852 & $<0,001$ & & \\
\hline Yd & Minat mempromosikan wakaf uang & 0,798 & $<0,001$ & & \\
\hline Ye & Minat berwakaf uang tanpa batas nominal & 0,855 & $<0,001$ & & \\
\hline Sumber & Data diolah (2020) & & \\
\hline
\end{tabular}

Sumber: Data diolah (2020)

\section{Evaluasi Inner Model}

Evaluasi inner model meliputi model fit test, path coefficient, dan $\mathrm{R}^{2}$. Model fit test digunakan untuk mengukur kecocokan suatu model dengan data penelitian. Berikut ini adalah hasil model fit test dan kriteria pengukurannya yang tersaji dalam Tabel 8.

Tabel 8. Hasil Pengujian Inner Model

\begin{tabular}{|l|c|c|c|c|}
\hline Keterangan & Hasil & P-values & Kriteria & Status \\
\hline APC & 0,271 & $<0,001$ & $\mathrm{P}<0,05$ & Terpenuhi \\
\hline ARS & 0,498 & $<0,001$ & $\mathrm{P}<0,05$ & Terpenuhi \\
\hline AARS & 0,490 & $<0,001$ & $\mathrm{P}<0,05$ & Terpenuhi \\
\hline AVIF & 2,180 & - & Value $<5$, ideally 3,3 & Terpenuhi \\
\hline AFVIF & 2,078 & - & Value $<5$, ideally 3,3 & Terpenuhi \\
\hline GoF & 0,553 & - & Medium $>0.25$, large $>0.36$ & Terpenuhi \\
\hline SPR & 1,000 & - & Acceptable if $>0,7$, ideally 1 & Terpenuhi \\
\hline RSCR & 1,000 & - & Acceptable if $>0,9$, ideally 1 & Terpenuhi \\
\hline SSR & 1,000 & - & Acceptable if $>0,7$ & Terpenuhi \\
\hline NLBCDR & 1,000 & - & Acceptable if $>0,7$ & Terpenuhi \\
\hline
\end{tabular}

Sumber: Data diolah (2020)

Hasil output diatas, menjelaskan bahwa Average path coefficient (APC), memiliki indeks sebesar 0,271 dengan $\mathrm{P}$-value kurang dari 0,001 . Average $R$ squared (ARS) memiliki indeks sebesar 0,498 dengan P-value kurang dari 0,001. Sedangkan Average adjusted $R$-squared (AARS) memiliki indeks sebesar 0,490 dengan P-value kurang dari 0,001. Average block VIF (AVIF) memiliki indeks sebesar 2,180; Average full collinearity VIF (AFVIF) memiliki indeks sebesar 2,078; Tenenhaus GoF (GoF) memiliki indeks sebesar 0,553; Sympson's paradox ratio (SPR) 
memiliki indeks sebesar 1,$000 ; R$ squared contribution ratio (RSCR) memiliki indeks sebesar 1,000; Statistical suppression ratio (SSR) memiliki indeks sebesar 1,000 dan Nonlinear bivariate causality direction ratio (NLBCDR) memiliki indeks sebesar 1,000. Berdasarkan kriteria yang disebutkan diatas maka nilai inner model telah terpenuhi (Kock, 2020)

\section{Uji Hipotesis}

Nilai $\mathrm{R}^{2}$ pada model menyatakan bahwa tiga variabel pengetahuan (X1), informasi (X2) dan religiusitas mampumenjelaskan varians minat berwakaf uang sebesar 50 persen. Berikut ini adalah hasil analisis jalur yang diperoleh dari hasil pengolahan data dengan menggunakan perangkat lunak Warp-PLS 7.0 :

Pengujian Hipotesis

Gambar 1. Hasil

Sumber: Warp-PLS diolah (2020)

Berdasarkan analisis data yang telah dilakukan terlihat bahwa persepsi pengetahuan berpengaruh positif dan

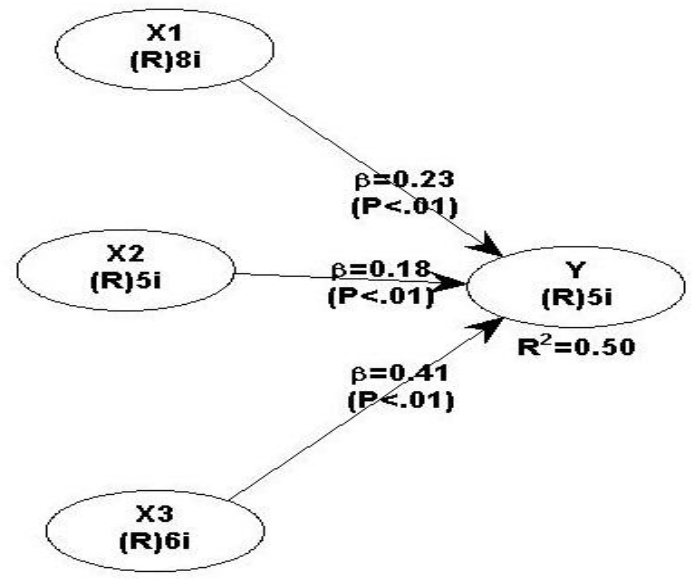

signifikan terhadap minat berwakaf uang $\quad(b=0,220 ; p$-value $<0,001)$. Demikian juga halnya dengan persepsi informasi $(b=0,177 ; p$-value $=0,007)$, dan persepsi religiusitas $(b=0,407$; $p$ value $<0,001$ ). Dengan demikian, dapat dikatakan bahwa semua variable memiliki pengaruh positif dan signifikan terhadap minat berwakaf uang. Pengaruh yang paling besar terhadap minat berwakaf uang adalah religiusitas, dengan nilai koefisien 0,407. Hasil lengkap pengujian hipotesis tersaji pada Tabel 9.

Tabel 9. Hasil Pengujian Hipotesis

\begin{tabular}{|c|l|c|c|c|}
\hline Hipotesis & \multicolumn{1}{|c|}{ Uraian } & Path & P-Value & Hasil \\
\hline $\mathrm{H}_{1}$ & $\begin{array}{l}\text { pengetahuan (X1) berpengaruh } \\
\text { terhadap minat berwakaf uang (Y) }\end{array}$ & 0,229 & $<0,001$ & Diterima \\
\hline $\mathrm{H}_{2}$ & $\begin{array}{l}\text { Informasi (X2) berpengaruh } \\
\text { terhadap minat berwakaf uang (Y) }\end{array}$ & 0,177 & 0,007 & Diterima \\
\hline $\mathrm{H}_{3}$ & $\begin{array}{l}\text { Religiusitas (X3) berpengaruh } \\
\text { terhadap minat berwakaf uang (Y) }\end{array}$ & 0,407 & $<0,001$ & Diterima \\
\hline
\end{tabular}

Sumber: Data diolah (2020)

\section{PEMBAHASAN}

Pengetahuan berpengaruh positif terhadap minat berwakaf uang. Hasil penelitian ini sejalan dengan hasil penelitian dari Handayani \& Kurnia, (2015), Nugroho \& Nurkhin, (2019), dan Sahal et al.,( 2020), namun berlawanan dengan hasil penelitian dari Falahuddin et al., (2019). Dapat dikatakan bahwa pengetahuan dapat memberikan knowledge claims dalam hubungannya dengan minat berwakaf uang. Informasi berpengaruh positif terhadap minat berwakaf uang, hasil ini sejalan hasil penelitian dari Handayani 
dan Kurnia (2015) yang menyatakan bahwa media informasi merupakan salah satu faktor yang membedakan minat masyarakat untuk melakukan wakaf. Religiusitas berpengaruh positif terhadap minat berwakaf uang, hasil ini sesuai dengan hasil penelitian dari Satrio (2016) dan Ash-Shidiqqy (2019) yang menyatakan bahwa religiusitas berpengaruh terhadap minat membayar zakat dan wakaf.. Dalam penelitian lainnya, religiusitas memang banyak memberikan pengaruh signifikan terhadap minat berbuat kebaikan. Penelitian yang dilakukan (Jayanto \& Munaroh, 2019) menyatakan bahwa semakin tinggi religiusitas dan kepercayaan orang yang berzakat (muzaki) terhadap organisasi pengelola zakat, semakin tinggi minat membayar zakat melalui organisasi pengelola zakat tersebut. Berdasarkan hal tersebut diatas, maka sosialisasi dan edukasi kepada masyarakat perlu dilakukan untuk meningkatkan pemahaman masyarakat tentang wakaf uang dengan harapan minat masyarakat untuk berwakaf uang semakin tinggi.

\section{SIMPULAN DAN IMPLIKASI}

Penelitian ini menemukan bahwa persepsi pengetahuan, informasi dan religiusitas berpengaruh positif dan signifikan terhadap minat berwakaf uang. Untuk lebih meningkatkan minat masyarakat dalam berwakaf uang perlu dilakukan promosi, sosialisasi dan juga edukasi yang cukup intens. Kerjasama pemerintah sebagai regulator beserta Majelis Ulama Indonesia (MUI) sebagai lembaga swadaya masyarakat di bidang keagamaan tentu sangat diperlukan dalam mengangkat potensi wakaf uang bukan hanya sebagai solusi perekonomian masyarakat namun juga dapat menjadi salah satu cara alternatif mencapai kesejahteraan masyarakat dalam jangka panjang.

Saran bagi pemerintah sebagai regulator adalah dengan membuat aturan atau undang-undang yang mengatur teknis terkait wakaf uang dan juga ikut mensosialisasikan lewat berbagai media cetak maupun elektronik. Bagi Majelis Ulama Indonesia (MUI) sebagai salah satu sumber fatwa bagi masyarakat agar dengan intens menyampaikan informasi dan fatwa kontemporer terkait wakaf uang karena fatwa sejenis jarang dirilis dan diketahui masyarakat sehingga masyarakat ragu untuk berwakaf uang dan bahkan mungkin saja ada ketidaktahuan terhadap kebolehan wakaf uang. Penelitian ini tentu banyak sekali kekurangan, mudah-mudahan penelitian sejenis dapat membuka banyak cakrawala baru dalam menyebarkan kemashlahatan bagi umat. Implikasi manajerial bagi para pengurus Lembaga wakaf, sesuai dengan hasil penelitian ini adalah dengan memperkuat sosialisasi untuk meningkatkan pengetahuan masyarakat terkait dengan pentingnya wakaf uang. Selain itu juga dengan memperbanyak informasi dengan

\section{DAFTAR PUSTAKA}

Achru, A. (2019). Pengembangan Minat Belajar Dalam Pembelajaran. Idaarah: Jurnal Manajemen Pendidikan, 3(2), 205. https://doi.org/10.24252/idaarah.v3i2.10012

Ashari, R. G. (2014). Memahami Hambatan dan Cara Lansia. Jurnal Ilmu Komunikasi, 15(2), 155-170.

Bolisani, E., \& Bratianu, C. (2018). Emergent knowledge strategies: Strategic thinking in knowledge management. In Springer International Publishing (Issue July). https://doi.org/10.1007/978-3-319-60656 
Falahuddin, F., Fuadi, F., \& Ramadhan, M. R. (2019). Faktor-Faktor yang mempengaruhi Minat Wakaf Masyarakat di Kota Lhokseumawe. Jurnal Ekonomi Dan Manajemen Teknologi (EMT), 3(2), 81. https://doi.org/10.35870/emt.v3i2.111

Handayani, R. P., \& Kurnia, T. (2015). Analisis Persepsi Masyarakat Kota Bogor Terhadap Wakaf Tunai. Jurnal Syarikah: Jurnal Ekonomi Islam, 1(2), 61-70. https://doi.org/10.30997/jsei.vli2.256

Hidayatullah, S. (2016). Wakaf Uang Dalam Perspektif Hukum Islam dan Hukum Positif di Indonesia. SALAM: Jurnal Sosial Dan Budaya Syar-I, 3(1), 1-20. https://doi.org/10.15408/sjsbs.v3i1.3306

Jayanto, P. Y., \& Munaroh, S. (2019). The Influences of Reputation, Financial Statement Transparency, Accountability, Religiosity, and Trust on Interest in Paying Zakat of Profession. Jurnal Dinamika Akuntansi, 11(1), 59-69. https://doi.org/10.15294/jda.v11i1.18729

Kock, N. (2020). WarpPLS 7.0 user manual. ScriptWarp Systems.

Kock, N., \& Hadaya, P. (2018b). Minimum sample size estimation in PLS-SEM: The inverse square root and gamma-exponential methods. Information Systems Journal, 28(1), 227-261. https://doi.org/10.1111/isj.12131

Kock, N., \& Lynn, G. S. (2012). Lateral Collinearity and Misleading Results in Variance-Based SEM : An Illustration and Recommendations Lateral Collinearity and Misleading Results in Variance-. Journal of the Association for Information Systems, 13(7), 546-580.

Kominfo. (2017). Survey Penggunaan TIK Serta Implikasinya Terhadap Sosial Budaya Masyarakat. Badan Penelitian Dan Pengembangan Sumber Daya Manusia, 1-30.

Madden, A. D. (2000). A definition of information. Aslib Proceedings, 52(9), 343-349. https://doi.org/10.1108/EUM0000000007027

Nasution, M. E. (2005). Wakaf Tunai Inovasi Finansial Islam. Pusat Kajian Timur tengah dan Islam - Universitas Indonesia.

Nugroho, A. S., \& Nurkhin, A. (2019). Pengaruh Religiusitas, Pendapatan, Pengetahuan Zakat Terhadap Minat Membayar Zakat Profesi Melalui Baznas dengan Faktor Usia Sebagai Variabel Moderasi. Economic Education Analysis Journal, 8(3), 955-966. https://doi.org/10.15294/eeaj.v8i3.35723

P., A. A. (2019). Pengembangan Minat Belajar Dalam Pembelajaran. Idaarah: Jurnal Manajemen Pendidikan, 3(2), 205. https://doi.org/10.24252/idaarah.v3i2.10012

Pemerintah Provinsi Jawa Barat. (2020). MES Harus Menjadi Dinamisator Ekonomi Syariah di Jabar. Pemerintah Provinsi Jawa Barat.

Pikiran Rakyat. (2019, November). Upah Minimum Kota/Kabupaten Jabar Tahun 2020.

Putri, A. F. (2018). Pentingnya Orang Dewasa Awal Menyelesaikan Tugas Perkembangannya. SCHOULID: Indonesian Journal of School Counseling, 3(2), 35. https://doi.org/10.23916/08430011

Sahal, A., Huda, N., \& Setianingrum, A. (2020). Analisis faktor yang mempengaruhi masyarakat muslim melakukan wakaf saham 1,2,3. 12(1). https://doi.org/10.35313/ekspansi.v12i1.1860 